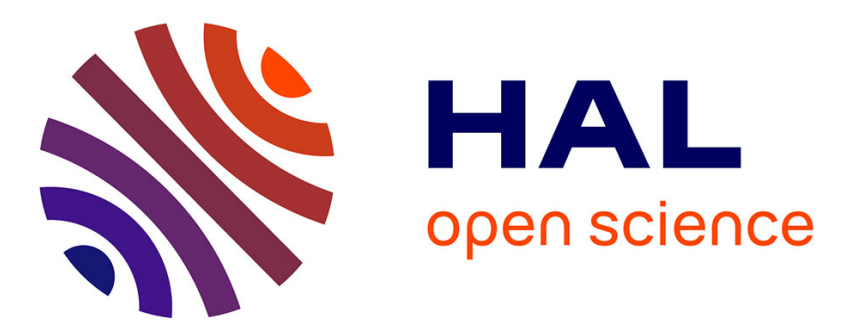

\title{
Simulation and evaluation of GM and non-GM segregation management strategies among European grain merchants \\ François Coléno
}

\section{- To cite this version:}

François Coléno. Simulation and evaluation of GM and non-GM segregation management strategies among European grain merchants. Journal of Food Engineering, 2008, 88 (3), pp.306-314. 10.1016/j.jfoodeng.2008.02.013 . hal-00410683

\section{HAL Id: hal-00410683 \\ https://hal.science/hal-00410683}

Submitted on 24 Aug 2009

HAL is a multi-disciplinary open access archive for the deposit and dissemination of scientific research documents, whether they are published or not. The documents may come from teaching and research institutions in France or abroad, or from public or private research centers.
L'archive ouverte pluridisciplinaire HAL, est destinée au dépôt et à la diffusion de documents scientifiques de niveau recherche, publiés ou non, émanant des établissements d'enseignement et de recherche français ou étrangers, des laboratoires publics ou privés. 

management strategies among European grain merchants.

3 F.C Coléno

4 INRA UMR 1048 SAD-APT. Site de grignon, BP1 78850 Thiverval-Grignon. France. E-mail

5 coleno@grignon.inra.fr

\section{Abstract}

7 Considering the European regulations, a product need to be labelled as containing GM when 8 the adventitious presence of GM material exceed $0.9 \%$. During collection, crops from many 9 fields are combined to fill a silo. Three management strategies to avoid the risk of mixing GM and non-GM crops were identified by a descriptive work based on cases studies in various

11 region of France: defining GM and non-GM silos and production zones; specifying the timing 12 of GM and non-GM crops delivery at silos; or using local management rules at each stage of 13 the supply-chain. To evaluate these strategies and to compare them to the actual supply chain 14 management we propose a model of elevators' supply-chain management. The allocation of 15 specific silos to GM and non-GM crops allows all the non-GM production to be segregated, 16 but with a $400 \%$ increase in transportation cost. Specifying the timing of GM and non-GM 17 crops deliveries allows all the non-GM crops to be segregated without any cost increase. Using local management rules does not allow more than $20 \%$ of the non-GM crops to be 19 segregated without an increase in costs.

21 Keywords : GMO, coexistence, segregation, supply chain 


\section{Introduction}

Growing GM crops in Europe generated conflict between proponents and opponents of this technology (Levidow et al., 2000). This conflict led at first to a moratorium on GM crops, which ended in 2004, and later to the principle of coexistence between the different types of crops in the landscape and to segregation of the GM and non-GM material in the supplychain. Several European regulations define the rules of coexistence and segregation:

- For the consumer information the aims of these regulation is to guarantee that any food containing material that contains more than $0.9 \%$ of GM would be labeled as “contains GM" (EC 2003a).

- for food industry the objective is to enable the traceability of GM products throughout the supply chain (from farmer to fork) (EC, 2003b),

- At the level of agricultural production, this regulation concerns the release in the environment of GMO (EC, 2001) and so to avoid cross-pollination between GM and non GM crops (EC, 2003c).

For agricultural production, this coexistence generates several problems. On a farm, use of the same agricultural machinery, such as a seed drill or harvester, for both GM and conventional production, increases the risk of admixture (Jank et al. 2006). Moreover, a farmer using GM seed has to be sure that his fields will not contaminate the conventional production of his neighbors. To do so different crop management are possible. A first one is to have isolation distance between GM and non-GM fields (Byrne and Fromherz, 2003) because maize pollen has a short flight range (Della Porta et al, in press). A second one is to define a time lag between GM and non-GM production so the flowering of GM and non-GM will not occur at the same moment (Messan et al., 2006).

At the industry level, the problem is to guarantee the level of GM material in the product. This is made using risk management policies based on such as HACCP (Scipioni et al. 2005) 
or IFMEA (Arvanitoyannis and Savelides, 2007) combine with testing procedures using quantitative methods such as PCR test (Lüthy 1999; Arvanitoyannis, 2006)

For maize production, the link between industry and farms is the country elevator, or grain merchant, whose infrastructure is the site of the highest mixing risk between GM and nonGM corps (Le Bail and Valceschini, 2004). Several critical points have been identified in this collection chain (Bullock and Dequilbet, 2002; Le Bail, 2003). These critical points are concerned with cropping plan management, storage of harvested products and, in the case of maize, drying, which is a bottleneck in maize collection. These critical points are linked with the fact that country elevators have to combine the production of several dozen fields in their collection silos and maize dryers. Furthermore, the batches obtained must be dealt with in less than 48 hours to protect the maize quality (Coléno et al., 2005). It is thus not possible to exclude batches by using the PCR test, which takes more than $48 \mathrm{~h}$. Moreover, the large investment necessary for the implementation of two isolated collection chains means that the GM and non-GM products need to be segregated using the existing infrastructure. Case studies showed that different companies use different collection strategies to minimize the risk of admixture. These strategies combine organization of crop production in the region and organization of the collection chain before harvest (Le Bail, 2003, Miraglia et al., 2004; Coléno et al., 2005). These strategies are based on:

- The separation of the two products in space, allocating one chain to each type of crop, so each collection silo receives only one type of product. Dryers are also allocated to one type of product.

- The separation of the two products by the timing of their deliveries. In this case, each product is delivered to the nearest collection silo to the farm, but at a specific time. Thus, non-GM can be delivered in the beginning of the collection period and the GM 
at the end. There is no risk of mixing between non-GM and GM, which might lead to downgrading of the non-GM crop.

These strategies are based on centralization of the decisions within the planning service of the country elevator. Landscape governance, resulting from a dialogue with the farmers (Byrnes and Fromherz, 2003) is needed to ensure such strategies.

Another way would be to decentralize the management of the coexistence to the various decision level of the supply chain. This leads to the use of specific scheduling rules at each decision level. Thee rules can be optimized in order to reduce the cost and to maximize the amount of product segregated (Entrup et al. 2005; Blanco et al., 2005; Higgins et al., 2006). This allows farmers to ignore the country elevators' constraints. In this paper, we propose to evaluate these management methods of decentralization and centralization using a simulation model of flow in the country elevator's supply chain for a large proportion of the non-GM grain collected. Concerning the method of centralization, we will take into account the two strategies of segregation in space and time. After presenting the model, we will evaluate the different strategies using two criteria: the collection cost and the proportion of non-GM that is stored as non-GM at the end of the collection process.

\section{The GM and non-GM maize collection chain}

Maize collection in Europe occurs in autumn - generally from September to December. During this period, farmers harvest their maize and deliver it to the collection silos of the firm purchasing their harvest. Each of these silos is made up of different cells, all of the same size. The cells are small compared to the quantity of maize collected. Very often, maize is transferred from collection silos to dryers. When maize is dried, it is stored in uniform batches in storage silos in seaports or railway stations. These storage silos may contain 300000 tons or more. To ensure a high quality of maize, and hence access to the best food markets, the maximum time from harvesting to drying should be less than 48 hours. To ensure GM and 
117 The collection silo model is shown in figure 1. Each day, a collection silo receives a quantity 118 of each product, $D_{t, p}$, where $p$ is the kind of product (GM or non-GM) and the time period.

non-GM segregation in the collection chain, several factors have been shown to be important (Le Bail 2003; Coléno et al 2005):

- Mixing of products can occur in the collection silos. When all the cells contain maize the silo manager has to choose between (i) accepting farmers' deliveries and thus mixing the two products or (ii) refusing some deliveries to avoid mixing but with the risk that the farmer will sell his crop to another firm. The type of relationship between the firm and the farmer, and whether there is another country elevator in the vicinity will influence the silo manager's decision.

- Mixing may also occur in the dryers. To reduce drying costs, dryers are used at their full capacity. In so doing, mixing may occur if there is not enough of one product. Moreover, to avoid contamination between products in the dryer, the first batch of non-GM that follows a GM lot must be sold as GM.

\section{Presentation of the model}

The model deals with these two critical points and takes into account transport between collection silos and dryers. It is therefore made up of three modules: collection silos, dryers and transport.

In order to take into account the decentralized method we will consider two schedulings of collections silos and dryers. The first one, in favor of segregation, consists of making uniform batches. Conversely, the second focuses on cost minimization using the total storage and drying capacity.

\subsection{Collection silos}

The delivery is then put into cells $\left(\mathrm{C}_{\mathrm{i}}\right)$ that contain the same product or are empty. If there is a 
rest when all the cells have been checked it's management depends on the silo's management strategy:

- In the case of scheduling in favor of segregation (SS1) the rest will be refused and deferred to the next day. So $D_{t+1, p}=D_{t+1, p}+D_{t, p}$.

- In the case of scheduling in favor of quantity maximization (SS2), the rest will be put in the first cell with sufficient free space. The maize in this cell will then be considered as GM.

\subsection{Transport}

Each day, the collection silos can call for transport if their stock is above a certain threshold (T):

If $\mathrm{C}_{\mathrm{i}} \geq \mathrm{T}$ then ask for transport.

These requests are treated using the First In First Out management rule, the older batch being given priority. To take into account the time constraint of 48 hours for the food market, the delivery stocked at t-1 has the higher priority level. If it is not possible to store the incoming batch in the waiting silos at the drying facility, the delivery is deferred to the next day.

\subsection{Dryers}

Drying facilities consist of two structures: dryer waiting silos, where maize is stored before being dried, and the actual dryers. Each day, a dryer dries one batch of maize. Changing the type of product dried $\left(\mathrm{DT}_{\mathrm{t}}\right)$ from one day to another can cause a loss (the first batch of nonGM following a GM batch is considered as GM). So the model tries first to minimize these changes. Each day the dryer has a waiting quantity $\left(\mathrm{WQ}_{\mathrm{t}}\right)$ of GM and non-GM to dry.

- In the case of the strategy in favor of segregation (SD1) the model works as shown in figure 2. The model will try to dry a batch of the same product that was dried in the previous period, even if it is not possible to use the dryer at its full capacity (DC). 
- In the case of the strategy in favor of cost minimization (SD2) the model works as shown in figure 3 . The model will try to use the dryer at its full capacity over each period, even if this causes a change in the type of product dried or a mixing of the two products.

\subsection{Variables used for simulation}

The model runs with a day time step. Each day, collection silo stocks are calculated, taking into account the GM and non-GM deliveries. GM and non-GM quantities dried are calculated, taking into account the waiting stock at the drying facility. From these new values of stocks in collection silos and dryer waiting silos, transport of maize from collection silos to drying facilities is calculated.

In order to run a simulation, we use the values shown in table 1 . These values are the ones we found in the country elevator we worked with (Coléno et al., 2005). The region we simulated contains ten collection silos and two dryers.

We first simulated the collection with $150000 \mathrm{t}$ of one product in order to compare the cost of a situation with segregation with the present situation (without segregation). The deliveries per day for the whole collection period in this case are shown in figure 4 . This curve is the ideal situation for country elevators. It comes from the combination of an optimal management of grain maturity and the desire of farmers and country elevators to harvest maize when it is as dry as possible.

Then we simulated three situations:

- One in which farmers can deliver their maize when and where they want (figure 5a).

- A spatial strategy whereby farmers can deliver their maize when they want to (figure 5a), but to a specific collection silo depending on the product (GM or non-GM). Each dryer is thus allocated to one type of product. The number of collection silos allocated to each type of product depends on the amount of non-GM grain in the deliveries. For 
example when non-GM represent $25 \%$ of the deliveries, $25 \%$ of the collection silos are allocated to non-GM.

- A temporal strategy whereby farmers can deliver their products where they want but non-GM crops are collected in the first part of the collection period and the GM crops are collected later (figure 5b).

174 For each of these situations we considered three distributions of GM and non-GM products in 175 the deliveries (non-GM representing 25, 33 and $50 \%$ of the total deliveries). Beyond $50 \%$ of non-GM in the total deliveries, the results would be reversed between non-GM and GM

177 because the question would be to isolate 25,33 or $50 \%$ of GM. For each of these three 178 situations we compared the quantity of each product (GM and non-GM) at the end of the 179 process to the quantity of the product delivered. To do so we calculated the ratio between 180 these two values. The ratio of GM can therefore be higher than $100 \%$ if there is non-GM crop 181 mixed with GM. To consider the cost we compared (i) the increase in transport cost compared 182 with the situation with one product and (ii) the rate of dryer use, which is a good indicator of 183 drying cost, as this cost is almost independent of the quantity dried.

\section{4. Results}

\section{$185 \quad 4.1$ advantage of the decentralized method}

186 Table 2 shows the percentage of the total deliveries treated without delivery planning.

187 We notice first that, in most cases, it is impossible to dry all the maize collected, so that some 188 is postponed to the next day. Some un-dried maize therefore remains at the end of the 189 collection period. This would be dried later but could not be sold in the most profitable market. 
Besides, we see that in every case the percentage of GM maize at the end of the process is more than $100 \%$. Hence some non-GM maize was mixed with GM. This is confirmed by the fact that the percentage of non-GM maize is below $100 \%$ in every case.

194 Hence we see that the collection silo decision rule in favor of segregation has a bigger effect on the amount of non-GM at the end of the process than the dryer decision rule in favor of

196 segregation. The amount of non-GM grain at the end of the process is greater when the SS1

197 rule is activated (55\% against $44 \%$ and $24 \%$ against $19 \%$ for $25 \%$ of non-GM for 198 example). It is at this level that mixing occurs first and thus affects the larger quantity. Dryer 199 management can only amplify the phenomenon.

200 Finally, we see that the combination of silo and dryer decision rules in favor of segregation 201 separates 51 to $61 \%$ of the non-GM maize with a small cost increase (figure 2).

\section{2 comparisons of the two collection strategies for the centralized method.}

\subsection{1 the spatial strategy}

In this case two different supply chains are created, one for non-GM maize and the other for

GM. One dryer is thus dedicated to each kind of maize. Depending on the proportion of non-

206 GM grain collected, $25 \%, 33 \%$ or $50 \%$ of the collection silos are dedicated to the non-GM 207 maize and the rest to GM maize.

208 Table 3 shows the proportions of GM and non-GM at the end of the collection process against 209 GM and non-GM at the beginning of the process.

210 The decentralized scheduling rules have no influence on the result when they are used with a 211 centralized scheme. The results are the same for all combinations of rules. There is therefore 212 nothing to be gained by combining these two methods.

213 The percentage of non-GM at the end of the process is above $90 \%$ in every case. But if non214 GM grain represents less than $50 \%$ of the total deliveries, the total amount of maize and the 
215 proportion of GM at the end of the process are lower than for the other strategies (see table 2,

2163 et 4). There is only one dryer allocated to GM. It is therefore not possible to dry all the GM

217 maize collected. Conversely, the size of the non-GM supply chain is greater than the total

218 non-GM deliveries, so the dryer is used below its capacity. This is confirmed by the high

219 drying cost (figure 7).

\subsubsection{Collection with a temporal strategy}

221 In this case, the non-GM crop is collected first and the GM is collected after. The duration of 222 the non-GM collection depends on its size.

223 As in the previous case, we see that the scheduling rules have no effect on the result. Indeed,

224 since the segregation is organized before deliveries to the silos, silos and dryers receive only one type of product. As a result, local management of segregation does not make sense.

226 Besides, the proportion of the deliveries treated is at least $96 \%$, according to the fraction of non-GM in the total deliveries. The proportion of the total deliveries treated increases with the amount of non-GM in the total deliveries.

229 However, when the non-GM represents $33 \%$ of the total deliveries, the proportion of non-GM segregated is low (72\%). In this case, the change from non-GM to GM occurs on day 30 , when the deliveries from farmers increase. To be able to collect all the deliveries, companies are compelled to mix the product in the silos and dryers.

\subsection{Cost of the different management strategies}

234 We then compare the increase in the costs of transport for the different segregation strategies

235 (Figure 6). This increase is calculated by a comparison with a collection of the same size with 236 only one product. This shows that the spatial strategy leads to an increase of 695 to $790 \%$ in 237 transport costs, depending on the fraction of non-GM maize in the deliveries. For this 238 strategy, each of dryers is allocated to one product (GM or non-GM). From then on, it is not 
possible to deliver batches from collection silos to the closest dryers. The temporal strategy

240 does not incur an increase in transport costs. On the other hand, the decentralized method

241 favoring segregation leads to an increase in transport costs of 22 to $50 \%$ depending on the

242 fraction of non-GM in the deliveries. This is because the batches are smaller, as management

243 rules are in favor of uniform batches. The number of journeys needed to deliver the same

244 quantity is thus greater.

245 Figure 7 presents the drying cost increase for the various management strategies.

246 The spatial strategy leads to a big increase in drying costs (from 17 to $34 \%$ ) when the fraction

247 of non-GM represents less than $50 \%$ of the deliveries. In such scenarios, each of the two 248 dryers is allocated to GM or non-GM. The one allocated to non-GM is not used at its maximal 249 capacity (which represents $50 \%$ of the deliveries). As the drying cost is largely fixed and 250 independent of the quantity dried, the drying cost per ton increases as the quantity dried 251 decreases. When non-GM grain represents $50 \%$ of the total deliveries, the dryers are used at 252 their maximum capacity and there is thus no increase in the drying cost.

253 The decentralized management method leads to a small increase in the drying costs (of 4 to $2547.7 \%$ ) because it is not possible to treat all the deliveries with this management method. The 255 refusal of a delivery at the collection silos leads to a decrease in the quantities collected, and 256 to an increase in the drying costs, as explained above. Also, the temporal strategy involves a 257 small increase in drying costs when non-GM is less than $50 \%$ of the total deliveries. This is 258 because the amount of maize to be dried is less than the one delivered to the collection silo. 259 This is due to the refusal of some of these deliveries. 


\section{Discussion}

261

262

263

264

265

266

267

268

\subsection{Comparison of the management strategies and consequences for the co-existence of}

\section{GM and non-GM crops}

The two centralized management strategies, which we evaluated using this model, arose from descriptive work on case studies in various regions of France (Coléno et al., 2005; Le Bail and Valceschini, 2004).

The results of this evaluation show that planning the collection to specialize infrastructures over time succeeded in isolating a big proportion of non-GM products for a small cost increase. However, with this strategy farmers are free to choose their type of crop without consulting the country elevators. As a result, the risk of gene-flow from GM fields to the nonGM ones can be high and lead to contamination of non-GM fields (Mésséan et al., 2006). This can be avoided using isolation between fields, but limits the farmer's choice, taking into account other farmers' choices in the neighborhood (Messéan et al., 2006; Devos et al., 2007). Moreover, this temporal strategy leads the farmers to harvest their crops at times decided by the country elevators, which may not include the optimal harvest date. This would be particularly true for the non-GM maize that is collected here first. The price paid to farmers for their harvest would therefore be reduced. Considering these consequences, this strategy would lead to a homogeneous region with the crop with the lesser constraint (Coléno et al., 2007).

With the spatial strategy on the other hand, certain part of the landscape are used for GM and others for non-GM (Coléno et al., 2007). The risk of cross-contamination is thus reduced (Angevin et al., in press). The choice of these zones according to the location of infrastructures (collection silos and dryers) would allow transport costs to be reduced as shown in this paper. However, such a strategy has an interest if the infrastructures are of appropriate size for the quantities collected. To ensure that this is the case, it is necessary to 
set up methods of land governance that involve farmers and country elevators in the choice of

286 the GM and non-GM location and the infrastructures dedicated to each production (Byrne and 287 Fromherz, 2003).

\subsection{Centralized management versus decentralized management}

289 We have compared here several methods of decentralized collection management with two 290 management strategies and several degrees of centralization.

291 For the spatial strategy, centralization of the collection planning concerns the whole supply 292 chain: decision rules are imposed on each member of the supply chain (the place of delivery 293 for farmers and trucks and the type of product to be handled for the silo and dryer managers).

294 Such a strategy leads to an increase in the costs for each of the cost centers, as they can't make 295 rules to reduce them. There is therefore no place for flexibility in the process, which leads to a 296 big cost increase (Bullock and Desquilbet, 2002).

297 A decentralized method does not lead to a loss of process flexibility or an increase in 298 collection costs, but to a small proportion of non-GM grain separated. Hence, if efficiency is 299 judged by the quality of production ( $\mathrm{Li}$ and Liu 2006), the use of decentralized scheduling 300 rules is less efficient over the course of time than centralized decisions based on forecasting. 301 It is therefore necessary to balance cost minimization and market satisfaction by the total non302 GM segregation. Such a compromise is made using the temporal strategy: a centralized 303 planning of the deliveries but with autonomy for the farmers and managers when making their 304 choices. It is a compromise between total centralization of the planning and decentralization, 305 allowing farmers to grow the best seed for their production system while ensuring segregation 306 of the two crops to satisfy both GM non-GM markets. This does not generate additional costs 307 at the various levels of the supply chain and allows decision centers to be as close as possible 308 to production and markets (Fennelly and Cormican, 2006). 


\section{Conclusion}

310 To overcome difficulties in segregation of GM and non-GM crops in the elevators' supply311 chain it is necessary to specialize the infrastructure (silos and dryers). This can be done by a

312 timing management of GM and non-GM deliveries or by defining GM and non-GM zones in 313 the region and its farming infrastructure.

314 These two typical solutions lead to an increase in the collection costs due to an increase in 315 transportation costs and a decrease in the flexibility of the collection process (Bullock and 316 Desquilbet, 2002). There is thus a trade-off in the distribution of this cost increase: will it be

317 borne by the consumer or shared out between the different members of the supply-chain, 318 especially the beneficiaries of GM technology?

319 Moreover, these strategies do not have the same effect on land organization in order to 320 minimize cross-pollination between GM and non-GM fields. The spatial strategy could allow 321 certain areas of land to be allocated to each product so as to minimize cross-pollination at 322 little cost to farmers. The temporal strategy would not lead to such a homogeneous landscape, 323 so the risk of cross-pollination would be greater.

324 Considering these difficulties of segregation management, it seems necessary to have a debate about land governance (Byrne and Fromherz, 2003) in order to define an optimal collection

326 strategy for country elevators that takes into account the cost management of the segregation 327 in the supply chain and GM land management.

\section{Acknowledgement}

329 Funding for this research was provided by the French Ministry or Research. 


\section{References}

331 Angevin, F., E.K. Klein, C. Choimet, A. Gauffreteau, C. Lavigne, A. Messéan, \& J.M.

332 Meynard. (in press). Modelling impacts of cropping systems and climate on maize cross

333 pollination in agricultural landscapes: The MAPOD model. European Journal of Agronomy.

334 Arvanitoyannis, I.S. (2006). Genetically Modified Plants: Applications and Issues In Editor.

335 Ray R.C, (ed), Microbial Biotechnology in Agriculture and Aquaculture Volume II., Science

336 Publishers, Enfield-Jersey-Plymouth, New Hampshire, USA pp.25-76.

337 Arvanitoyannis, I. S, \& Savelides, S.C. (2007). Application of failure mode and effect 338 analysis and cause and effect analysis and Pareto diagram in conjunction with HACCP to a 339 chocolate-producing industry: a case study of tentative GMO detection at pilot plant scale. $340 \quad$ International journal of food science and technology published online

341 Blanco, A.M.; Masini,G.; Petracci,N. \& Bandoni,J.A. (2005). Operations management of a 342 packaging plant in the fruit industry. Journal of Food Engineering. 70, 299-307

343 Bullock, D.S. \& Desquilbet M. (2002). The economics of non-GMO segregation and identity 344 preservation. Food Policy 27, 81-99.

345 Byrne, P. F. \& Fromherz, S. (2003) Can GM and Non-GM Crops Coexist? Setting a 346 Precedent in Boulder County, Colorado, USA, Journal of Food, Agriculture \& Environment, $347 \quad 1(2), 258-261$.

348 Coléno, F. C., le Bail, M. \& Raveneau, A. (2005). Segregation of GM and non-GM 349 production at the primary production level. In Messan A. (ed) proceeding of the Second 350 International Conference on Co-existence between GM and non-GM based agricultural 351 supply chain, Agropolis Production, Montpellier (FRA), 14-15/11/2005, pp. 169-172.

352 Coléno F.C., Angevin, F. \& Adamczyk K. (2007). Modeling farmer's choice to evaluate GM 353 and non-GM coexistence strategies at a territory level: case of maize production. In , Stein 
A.J., Rodriguez-Cerezo E. (eds) proceeding of the Third International Conference on Coexistence between GM and non-GM based agricultural supply chain., Sevilla (Spain), 2021/11/2007, pp. 141-144.

Della Porta G., Ederle D., Bucchini L., Prandi, M., Verderio A. \& Pozzi C. (in press) Maize pollen mediated gene flow in the Po valley (Italy): Source-recipient distance and effect of flowering time. European Journal of Agronomy.

360 Devos Y., Reheul, D., Thas, O., De Clercq, E. M., Cougnon, M., \& Cordemans, K. (2007). 361 Implementing isolation perimeters around genetically modified maize fields. Agronomy For Sustainable Development. 27, 155-165.

Entrup, M. L., Gunther, H. O., Van Beek, P., Grunow, M., \& Seiler, T. (2005). Mixed-Integer Linear Programming approaches to shelf-life-integrated planning and scheduling in yoghurt production, International Journal of Production Research 43 (23), 5071-5100.

European Commission (2001) Directive 2001/18/EC of the European Parliament and of the

Council of 12 March 2001 on the deliberate release into the environment of genetically modified organisms and repealing Council Directive 90/220/EEC - Commission Declaration Official Journal of the European Union L 106, 17.4.2001, pp. 1-39

European Commission, (2003a) Regulation (EC) $\mathrm{N}^{\circ} 1829 / 2003$ of the European Parliament 371 and of the Council of 22 September 03 concerning the traceability and labelling of genetically modified organisms and the traceability of food and feed products produced from genetically modified organisms and amending Directive 2001/18/EC. Official Journal of the European Union, 18/10/2003, vol. 46, L268, pp 1-23

European Commission, (2003b) Regulation (EC) No 1830/2003 of the European Parliament

376 and of the Council of 22 September 2003 concerning the traceability and labelling of 377 genetically modified organisms and the traceability of food and feed products produced from 
genetically modified organisms and amending Directive 2001/18/EC. Official Journal of the

379 European Union, 18/10/2003, vol 46, L268 pp24 - 28

380 European Commission, (2003c) Commission recommendations of 23 July 2003 on guidelines

381 for the development of national strategies and best practices to ensure the coexistence of 382 genetically modified crops with conventional and organic farming, 2003/556/EC (notified 383 under document number C(2003) 2624). Official Journal of the European Union, 29/07/2003, 384 vol. 46, L189, pp 36-47.

385 Fennelly D. \& Cormican, K. (2006). Value chain migration from production to product 386 centred operations: an analysis of the Irish medical device industry. Technovation, 26, 86-94.

387 Higgins, A. Beashel,G. \& Harrison, A. (2006). Scheduling of brand production and shipping 388 within a sugar supply chain. Journal of the Operational Research Society 57, 490-498

389 Jank, B., Rath, J. \& Spok, A. (2005). Genetically modified organisms and the EU, Trends in $390 \quad$ Biotechnology 23 (5), 222-224.

391 Jank, B., Rath, J. \& Gaugitsch, H. (2006). Co-existence of agricultural production systems, 392 Trends in Biotechnology 24 (5), 198-200.

393 Le Bail, M. (2003). GMO/non-GMO segregation in the supply zone of country elevators., in 394 proceedinf of the first Conference on the co-existence of Genetically Modified Crops with 395 Conventional and Organic Crops, Borupsgarrd(DNK), 13-14/11/2003 pp. 125-127.

396 Le Bail, M. \& Valceschini, E. (2004). Efficacité et organisation de la séparation OGM/non 397 OGM., Economie et Société. Série «systèmes agroalimentaires» 12 (4), 18-29.

398 Levidow, L., Carr, S. \& Wield, D. (2000). Gentically modified crops in the European Union: 399 regulatory conflicts as precautionary opportunities, Journal of Risk Research 3 (3), 189-208. 
400 Li, J. L. \& Liu, L. W. (2006). Supply chain coordination with quantity discount policy, 401 International Journal of Production Economics 101 (1), 89-98.

402 Lüthy, J. (1999). Detection strategies for food authenticity and genetically modified foods, 403 Food control 10, 259-361.

404 Messéan, A., Angevin, F., Gómez-Barbero, M., Menrad, K., \& Rodríguez-Cerezo, E. (2006). 405 New case studies on the coexistence of GM and non-GM crops in European agriculture, 406 Technical Report Series of the Joint Research Center of the European Commission, EUR $40722102 \mathrm{En}, 112 \mathrm{p}$.

408 Miraglia, M., Berdal, K.G., Brera, C., Corbisier, P., Holst-Jensen, A., Kok, E.J., Marvin, 409 H.J.P., Schimmel, H., Rentsch, J., Van Rie, J.P.P.F. \& Zagon, J. (2004). Detection and 410 traceability of genetically modified organisms in the food production chain. Food and 411 Chemical Toxicology 42, 1157-1180.

412 Scipioni, A., Saccarola, G., Arena, F. \& Alberto, S. (2005). Strategies to assure the absence of 413 GMO in food products application process in a confectionery firm, Food control 16, 569-578. 
414 Fig. 1: the collection silo model

415 Fig. 2: the dryer model for the scheduling strategy in favor of segregation (SD1). DT=type of

416 product dried, $\mathrm{WQ}=$ waiting quantity, $\mathrm{DC}=$ drying capacity, $\mathrm{S}=$ stock of product dried

417 Fig. 3: the dryer model for the scheduling strategy in favor of cost minimization (SD2).

418 DT=type of product dried, $\mathrm{WQ}=$ waiting quantity, $\mathrm{DC}=$ drying capacity, $\mathrm{S}=$ stock of dried

419 product

420 Fig. 4: deliveries per day for a collection with one product

421 Fig. 5: deliveries of GM and non-GM grain. The case of 33\% of non-GM in the collection. (a)

422 no strategy and spatial strategy. (b) temporal strategy

423 Fig. 6: increase in transport cost compared to collecting one product (without segregation) for

424 the three strategies or methods (the decentralized method is the one favoring segregation).

425 Fig. 7: increase of drying cost compared to a collection of one product (without segregation)

426 for the three strategies or logic 


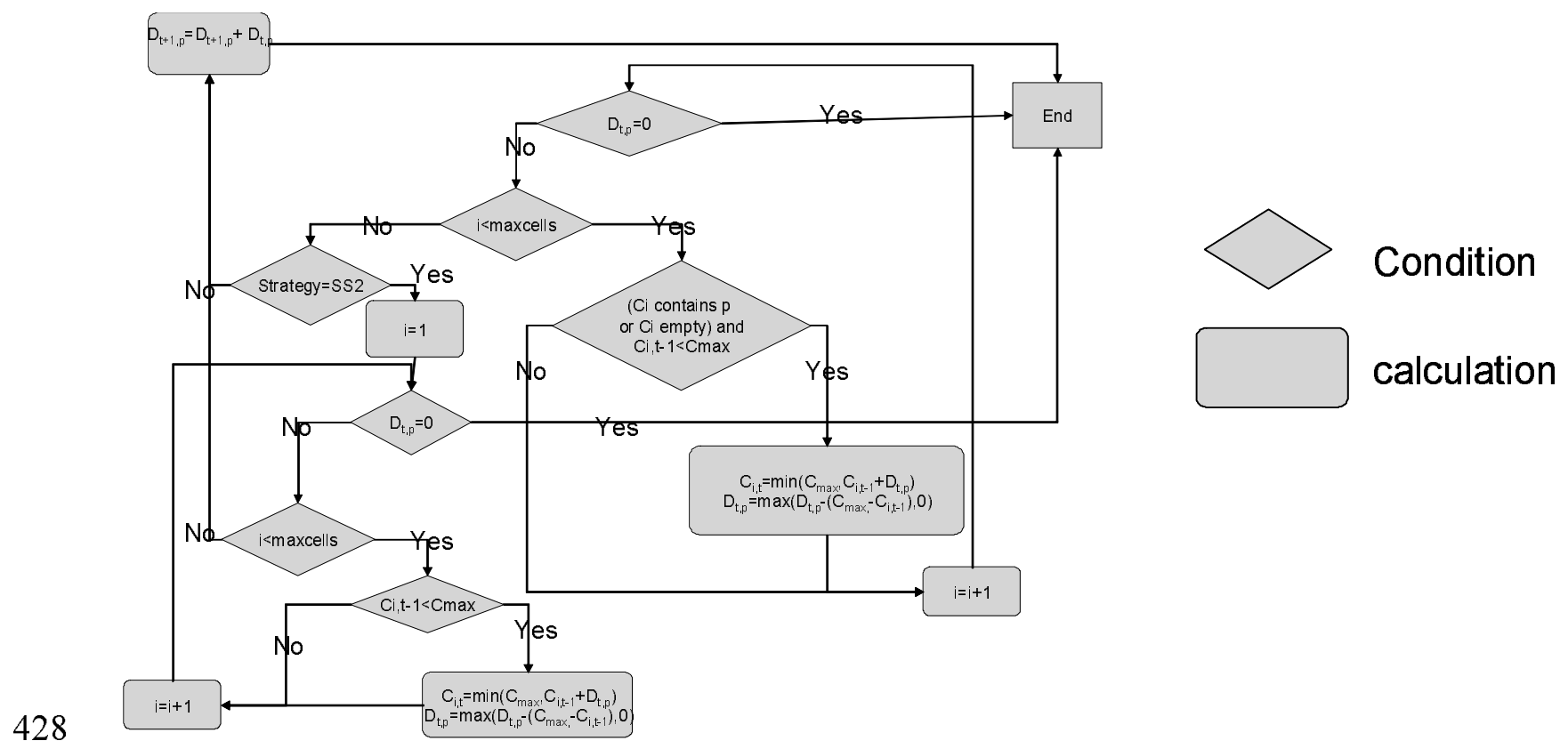

Fig. 1 


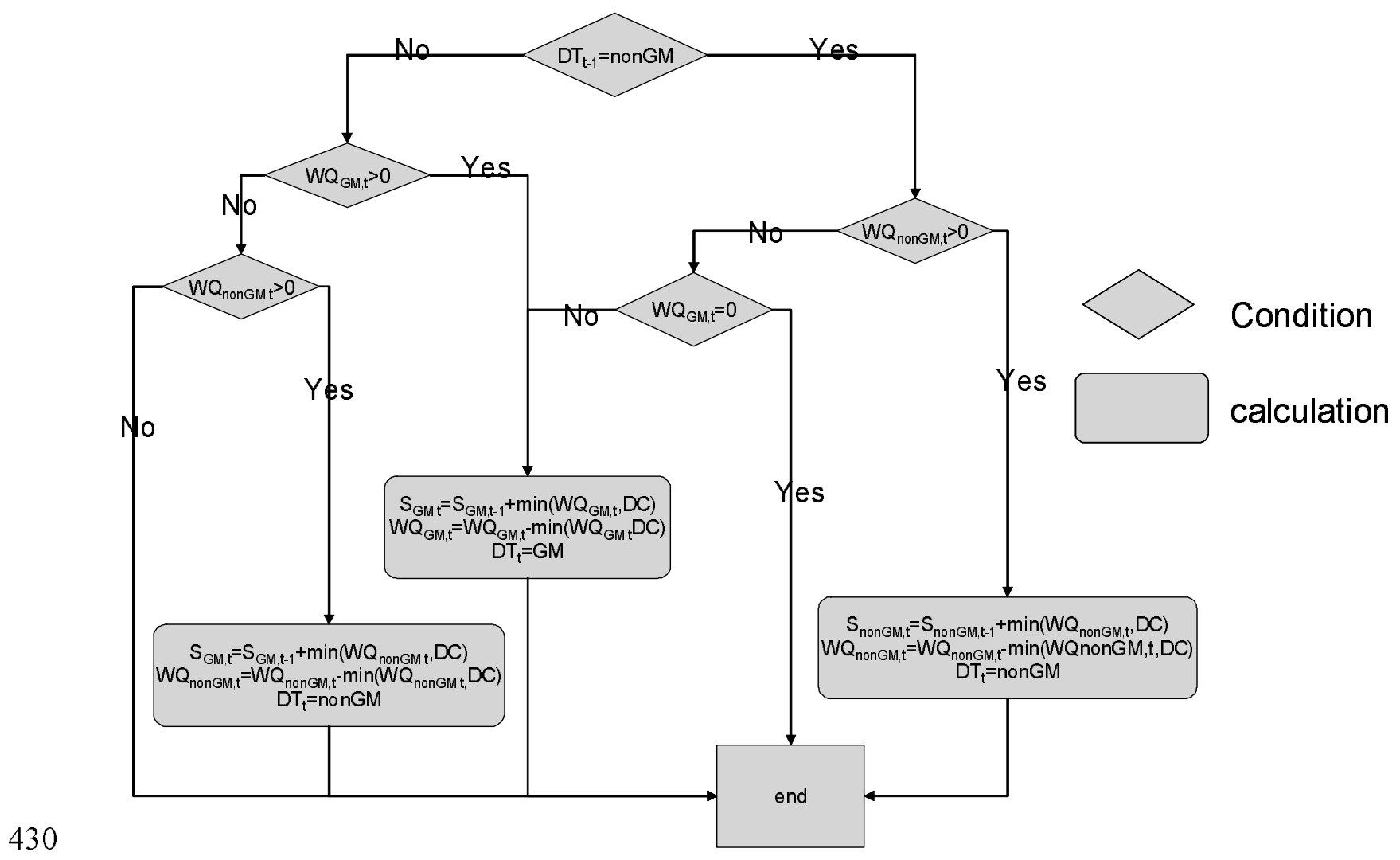

Fig. 2. 


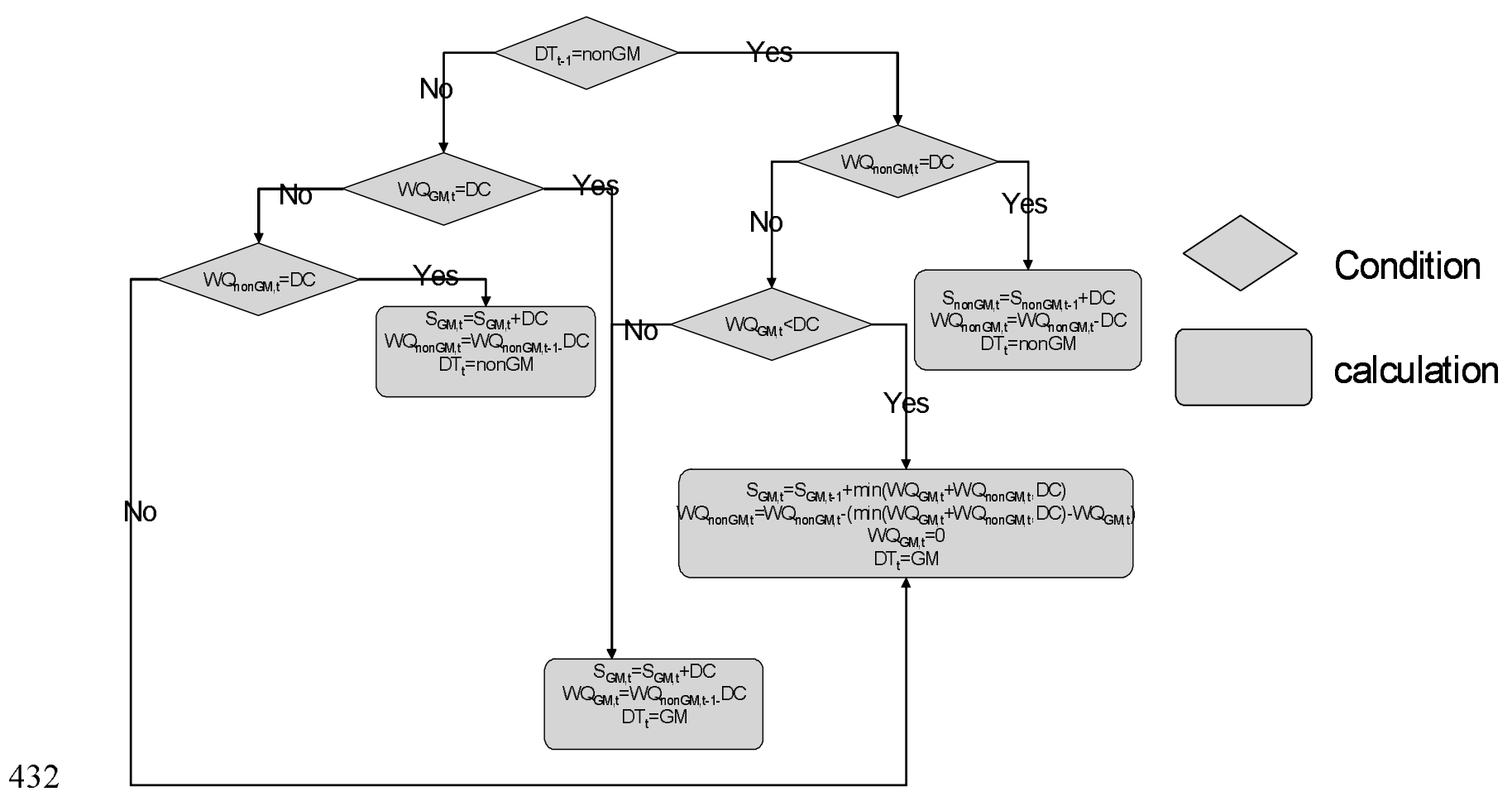

Fig. 3 


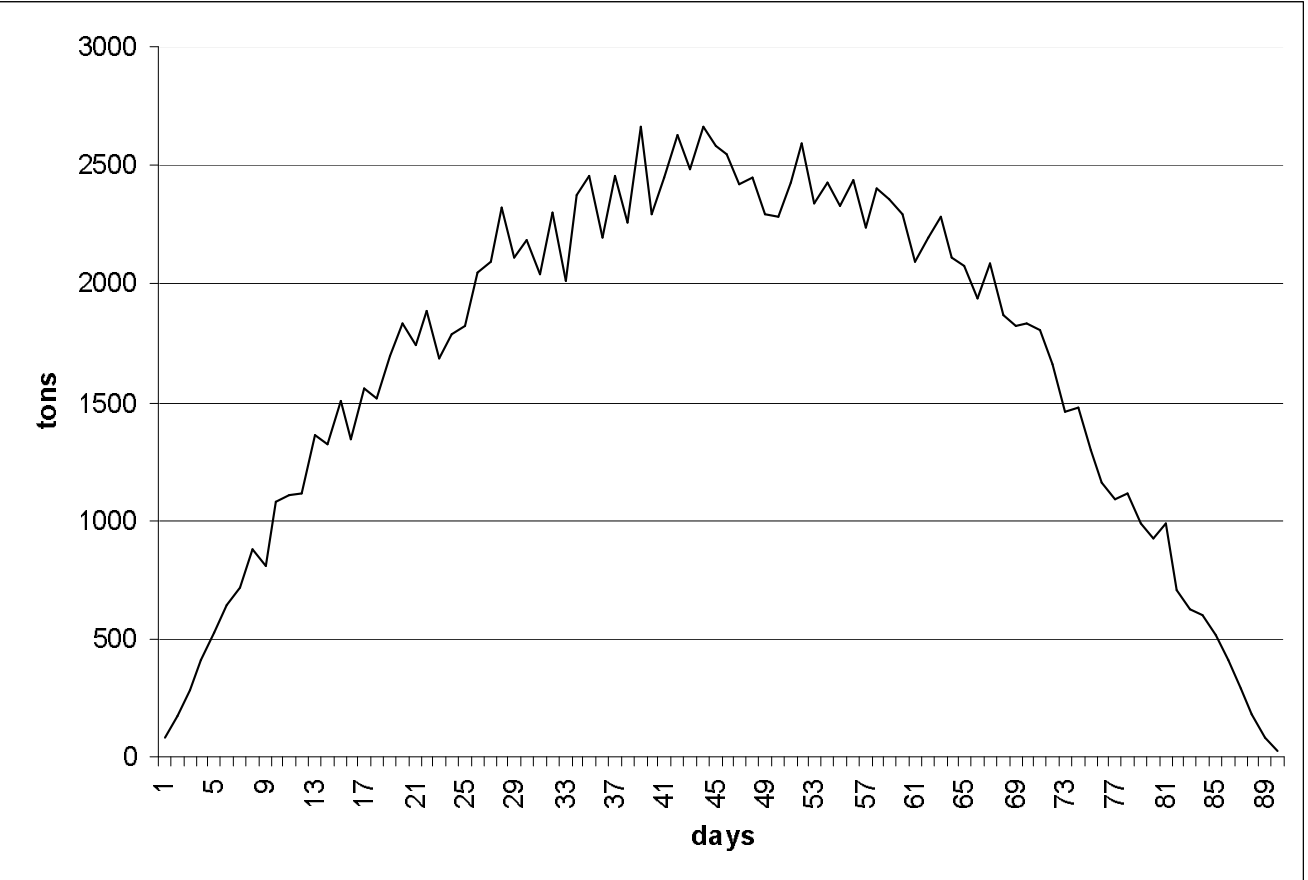

Fig. 4 

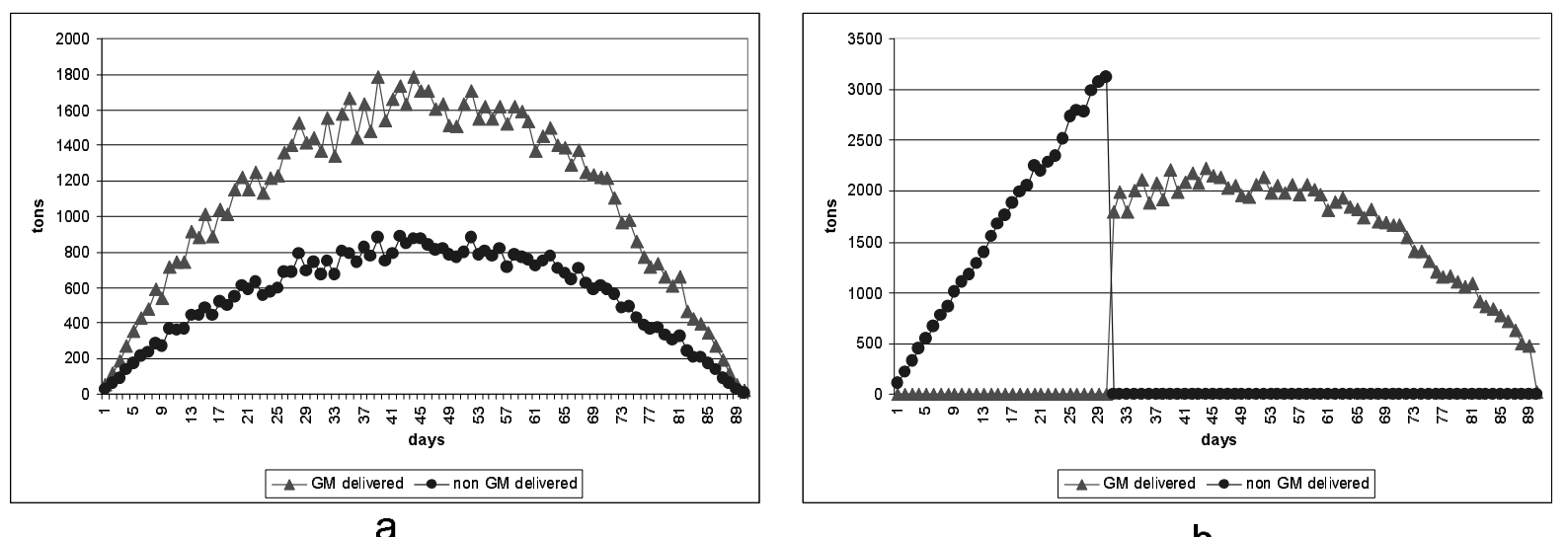

b

437

438

Fig. 5 


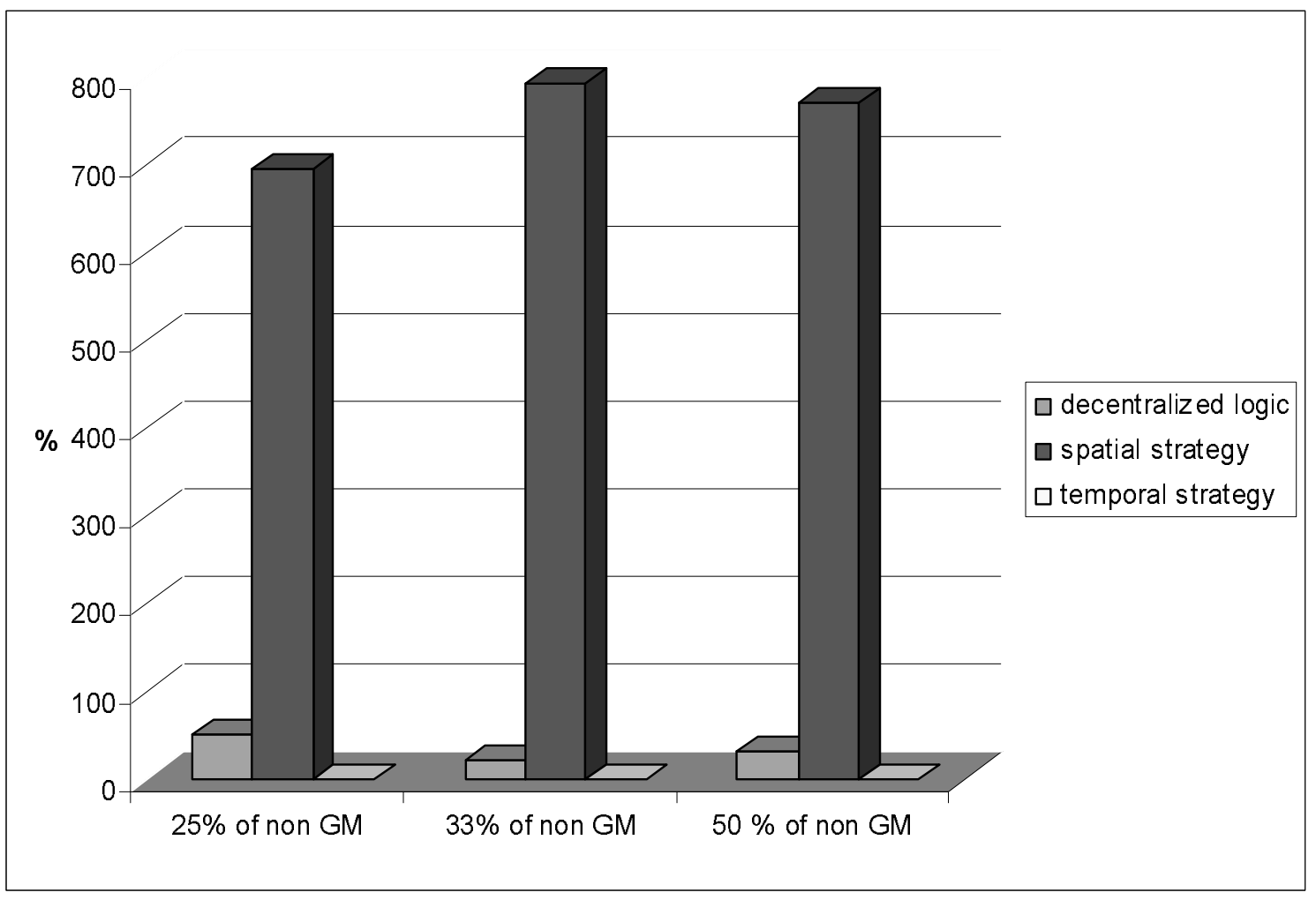

Fig. 6 


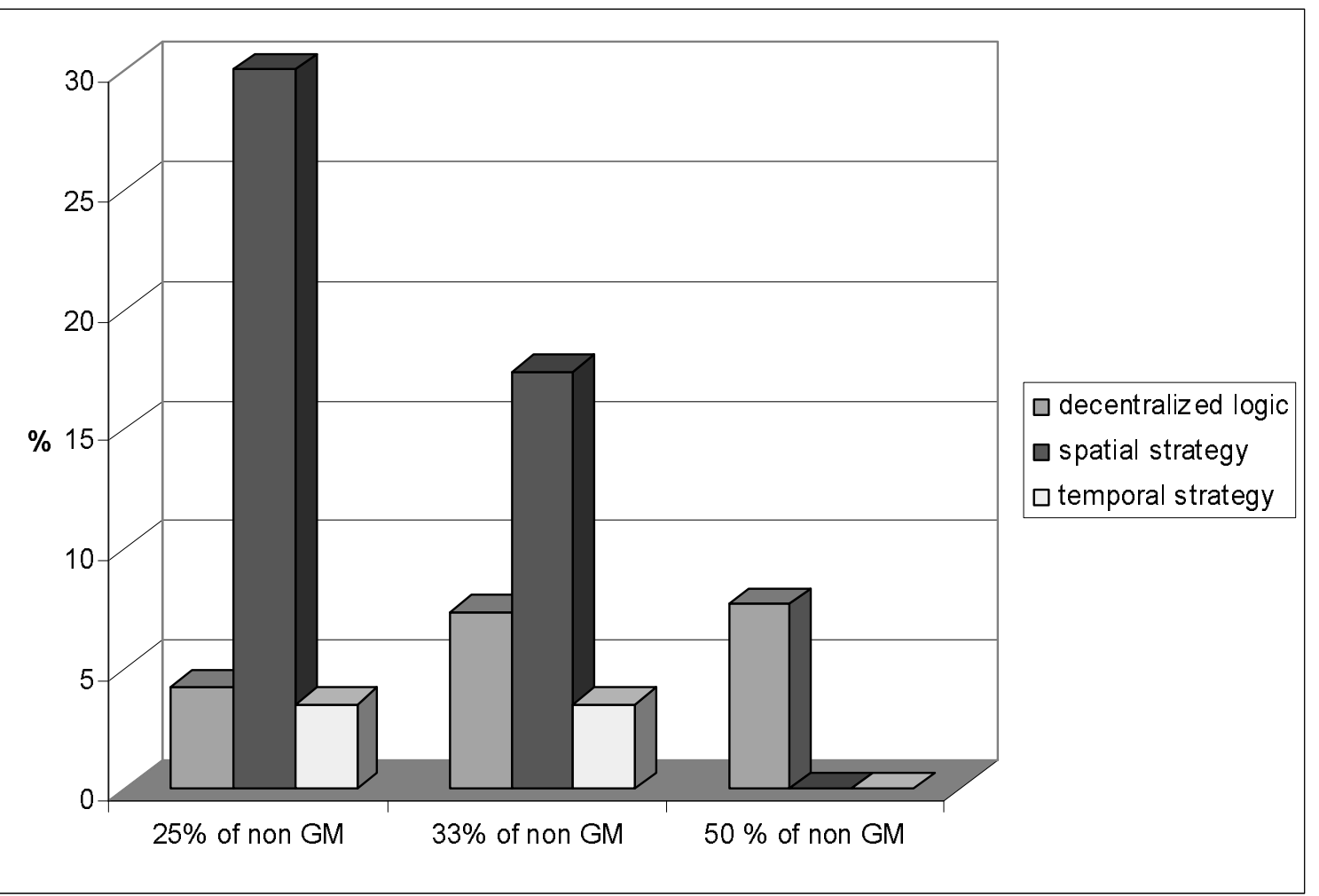

443

Fig. 7.

445 
446 Table 1: value of the different parameters

447 Table 2: Percentage of the total collection ( 1 ), GM ( 2 ) and of non-GM ( 3 ) at the end of the 448 process compared with the quantity at the beginning. The case of the decentralized method.

449 Table 3: Percentage of the total collection ( 1 ), GM ( 2 ) and of non-GM ( 3 ) at the end of the 450 process with regard to the quantity at the beginning. Case of the spatial strategy.

451 Table 4: Percentage of the total collection ( 1 ), GM ( 2 ) and of non-GM ( 3 ) at the end of the 452 process with regard to the quantity at the beginning. Time strategy case. 
453

\begin{tabular}{ll}
\hline Size of collection silos & $4 * 100 \mathrm{t}$ \\
Size of dryer waiting silos & $2 * 250 \mathrm{t}$ \\
Drying capacity & $1000 \mathrm{t} /$ day \\
Number of trucks & 30 \\
Size of trucks & $36 \mathrm{t}$ \\
Total size of collection & $150000 \mathrm{t}$
\end{tabular}

454

Table 1

455

456 
Silo scheduling rule in favor of segregation Silo scheduling rule in favor of quantity (SS1) maximization (SS2)

\begin{tabular}{|c|c|c|c|c|}
\hline & Dryer scheduling rule & Dryer scheduling rule & Dryer scheduling rule & Dryer scheduling rule \\
\hline & favor & in favor of quantity & favor & in favor of quantity \\
\hline & segregation (DS1) & maximization (DS2) & segregation (DS1) & maximization (DS2) \\
\hline $25 \%$ of & $96^{1} / 110^{2} / 55^{3}$ & $90^{1} / 112^{2} / 24^{3}$ & $97^{1} / 116^{2} / 44^{3}$ & $89^{1} / 112^{2} / 19^{3}$ \\
\hline \multicolumn{5}{|l|}{ non-GM } \\
\hline $33 \%$ of & $93^{1 / 114^{2} / 52^{3}}$ & $98^{1} / 131^{2} / 32^{3}$ & $88^{1} / 120^{2} / 26^{3}$ & $97^{1} / 135^{2} / 21^{3}$ \\
\hline \multicolumn{5}{|l|}{ non-GM } \\
\hline $50 \%$ of & $93^{1} / 123^{2} / 63^{3}$ & $100^{1} / 161^{2} / 39^{3}$ & $94^{1} / 156^{2} / 34^{3}$ & $100^{1} / 169^{2} / 31$ \\
\hline non-GM & & & & \\
\hline
\end{tabular}


Silo scheduling rule in favor of segregation Silo scheduling rule in favor of quantity (SS1) maximization (SS2)

\begin{tabular}{|c|c|c|c|c|}
\hline & Dryer scheduling rule & Dryer scheduling rule & Dryer scheduling rule & Dryer scheduling rule \\
\hline & in favor of & in favor of quantity & in favor of & in favor of quantity \\
\hline & segregation (DS1) & maximization (DS2) & segregation (DS1) & maximization (DS2) \\
\hline $25 \%$ of & $77^{1} / 73^{2} / 90^{3}$ & $77^{1} / 73^{2} / 90^{3}$ & $77^{1} / 73^{2} / 90^{3}$ & $77^{1} / 73^{2} / 90^{3}$ \\
\hline non-GM & & & & \\
\hline $33 \%$ of & $85^{1} / 82^{2} / 91^{3}$ & $85^{1} / 82^{2} / 91^{3}$ & $85^{1} / 82^{2} / 91^{3}$ & $85^{1} / 82^{2} / 91^{3}$ \\
\hline non-GM & & & & \\
\hline $50 \%$ of & $99^{1} / 99^{2} / 100^{3}$ & $99^{1} / 99^{2} / 100^{3}$ & $99^{1} / 99^{2} / 100^{3}$ & $99^{1} / 99^{2} / 100^{3}$ \\
\hline
\end{tabular}


Silo scheduling rule in favor of segregation Silo scheduling rule in favor of quantity (SS1) maximization (SS2)

\begin{tabular}{|c|c|c|c|c|}
\hline & Dryer scheduling rule & Dryer scheduling rule & Dryer scheduling rule & Dryer scheduling rule \\
\hline & $\begin{array}{l}\text { in favor of } \\
\text { segregation (DS1) }\end{array}$ & $\begin{array}{l}\text { in favor of quantity } \\
\text { maximization (DS2) }\end{array}$ & $\begin{array}{l}\text { in favor of } \\
\text { segregation (DS1) }\end{array}$ & $\begin{array}{l}\text { in favor of quantity } \\
\text { maximization (DS2) }\end{array}$ \\
\hline $\begin{array}{l}25 \% \text { of } \\
\text { non-GM }\end{array}$ & $96^{1} / 97^{2} / 94^{3}$ & $96^{1} / 97^{2} / 94^{3}$ & $96^{1} / 97^{2} / 94^{3}$ & $96^{1} / 97^{2} / 94^{3}$ \\
\hline $\begin{array}{l}33 \% \text { of } \\
\text { non-GM }\end{array}$ & $97^{1} / 108^{2} / 72^{3}$ & $97^{1} / 108^{2} / 72^{3}$ & $97^{1} / 108^{2} / 72^{3}$ & $97^{1} / 108^{2} / 72^{3}$ \\
\hline $\begin{array}{l}50 \% \text { of } \\
\text { non-GM }\end{array}$ & $100^{1} / 100,4^{2} / 99.5^{3}$ & $100^{1} / 100,4^{2} / 99.5^{3}$ & $100^{1} / 100,4^{2} / 99.5^{3}$ & $100^{1} / 100,4^{2} / 99.5^{3}$ \\
\hline
\end{tabular}

